\title{
Laboratory Investigations into Stability and Breaching of Rockfill Dams
}

\author{
Geir Helge KIPLESUND ${ }^{\bowtie}$ and Fjola Gudrun SIGTRYGGSDOTTIR \\ Norwegian University of Science and Technology, \\ Department of Civil- and Environmental Engineering, Trondheim, Norway \\ geir.h.kiplesund@ntnu.no
}

\begin{abstract}
Laboratory investigations into the breaching of rockfill dams is an ongoing research at NTNU. The current model represents a full dam profile and is a development of earlier models used for investigating stability of rockfill dams and ripraps under throughflow and overtopping situations. Instrumentation of the model includes pore pressure measurements along the dam foundation, water level recording and video recording from multiple angles. Video is used to extract images at intervals throughout the breaching process and 3D models of the breach opening created using "structure from motion" and "multi view stereo" processing techniques. The overall aim is to enhance current knowledge on the breaching of rockfill dams. Modelling of the impervious element is a major challenge for the experiments and the process of finding an appropriate solution to this is described in the present study along with preliminary results.
\end{abstract}

Keywords: dam breach, rockfill dams, structure from motion.

\section{INTRODUCTION}

The current research is based on a continuous series of laboratory tests combined with some large-scale field tests and other field investigations starting in 2013. The original focus was on the stability of riprap on dams (Hiller et al. 2018, 2019). Further work was done on riprap stability as well as investigating throughflow in rockfill dams (Ravindra et al. 2019, 2020a,b), and how this affects overall stability and how different toe designs affect throughflow and stability (Kiplesund et al. 2021). One of the important outcomes of this research has been the description of failure mechanisms and quantification of the increased safety provided by dumped and placed ripraps as well as how the factor of safety is affected by the throughflow conditions in the downstream supporting fill. Present work is focused on breach initiation and development 
in rockfill dams. To describe breach development beyond the initiation a redesign of the model to incorporate a breachable core element rather than a fixed core as in earlier experiments was necessary. This work discusses the challenge relating to acceptable modelling of the impervious element, i.e. the core, and provides related results from SWOT analysis and pilot experiments. Some observations on breach development can also be drawn at this early stage from the completed tests.

\section{EXPERIMENTAL SETUP}

The rockfill dam model is situated in a $25 \mathrm{~m}$ long flume in the hydraulic laboratories at NTNU. Figure 1 shows the model setup. The breaching process is recorded with strategically located video cameras for creating 3D models using "structure from motion" and "multi view stereo". Additionally, pore pressures along the base, upstream water levels and inflow are recorded. The dam body comprises about $5000 \mathrm{~kg}$ of well graded rockfill, scaled from observed rock gradations in existing dams. Two main materials have been tested for the core: a tiled extruded foam core and a rubber membrane. The experiments are ongoing but currently a total of six pilot tests have been carried out. Currently the first test with a riprap protection is about to be performed.

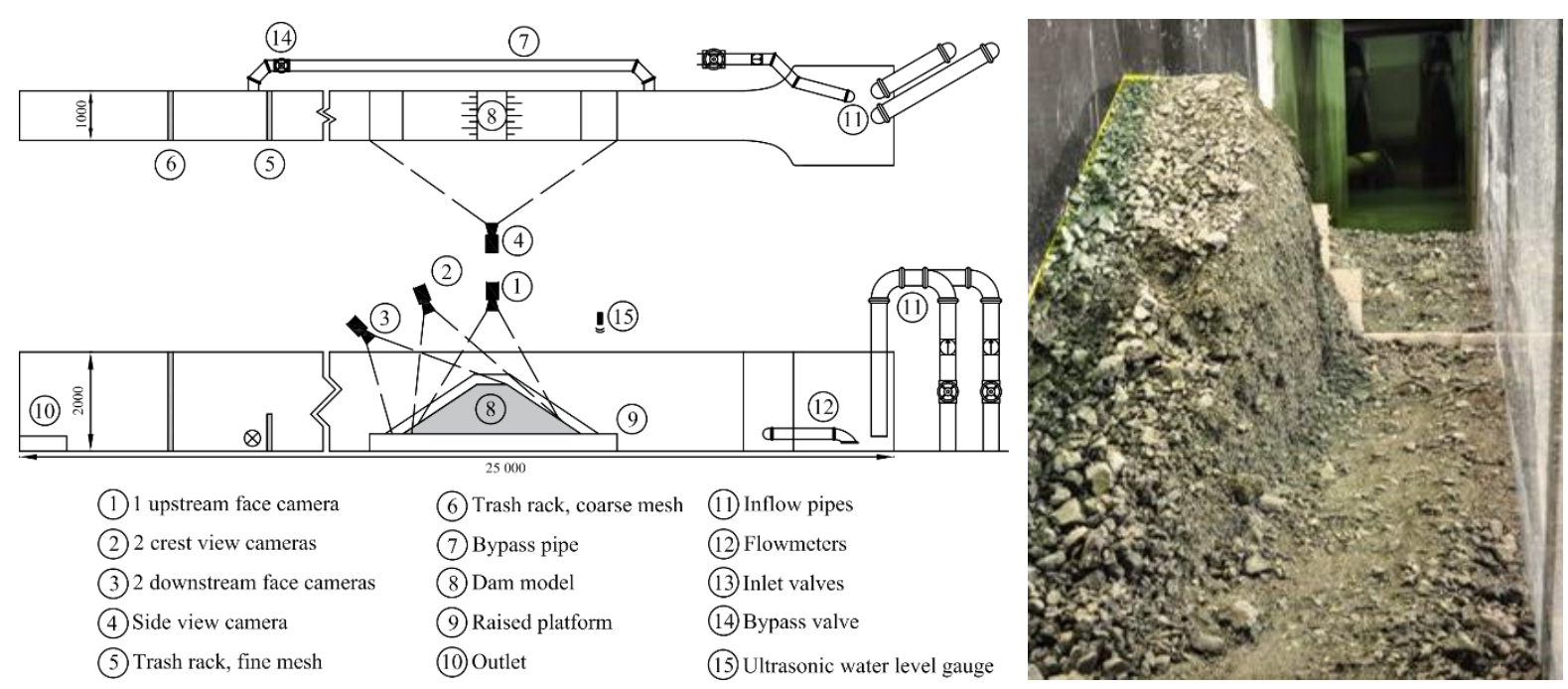

Fig. 1. Laboratory setup (left) and example of breached dam (right).

\section{ANALYSIS}

There are restrictions on the use of fines in the flume due to a circulation system. Consequently, the conditions do not allow for a realistic modelling of a clayey core. Hence, the main goal of the presented experiments is to realistically model the breach formation in the rockfill itself. Thus, different criteria for a successful test series were defined and included: a realistic phreatic line prior to and during the overtopping situation; reasonable effect of the watertight membrane on the breaching; and ease of separating the core material from the rockfill remains. A SWOT analysis was conducted in the selection process. Furthermore, a work process has been developed to analyse the breach process using 3D models created by extracting synchronized frames from the videos. Through this work many lessons have been learned on optimal camera settings, alignment, number of cameras, lighting, etc. 


\section{RESULTS}

The SWOT analysis aided in modelling strategically the watertight membrane. Analysis of data and videos from the experiments supported the selected strategy and has proven to be important in analysis of the breach process. The main outcome is that the research can continue with the rockfill, adding riprap on the dam slopes to further investigate the effect of riprap erosion protection on the breaching process using the selected instrumentation and tools.

Acknowledgments. Financial support from HydroCen is acknowledged.

\section{References}

Hiller, P.H., J. Aberle, and L. Lia (2018), Displacements as failure origin of placed riprap on steep slopes, J. Hydraul. Res. 56, 2, 141-155, DOI: 10.1080/00221686.2017.1323806.

Hiller, P.H., L. Lia, and J. Aberle (2019), Field and model tests of riprap on steep slopes exposed to overtopping, J. Appl. Water Eng. Res. 7, 2, 103-117, DOI: 10.1080/23249676.2018.1449675.

Kiplesund, G.H., G.H.R. Ravindra, M.M. Rokstad, and F.G. Sigtryggsdottir (2021), Effects of toe configuration on throughflow properties of rockfill dams, J. Appl. Water Eng. Res., DOI: 10.1080/23249676.2021.1884615.

Ravindra, G.H.R., F.G. Sigtryggsdóttir, and Ø.A. Høydal (2019), Non-linear flow through rockfill embankments, J. Appl. Water Eng. Res. 7, 4, 247-262, DOI: 10.1080/23249676.2019.1683085.

Ravindra, G.H.R., O. Gronz, J.B. Dost, and F.G. Sigtryggsdóttir (2020a), Description of failure mechanism in placed riprap on steep slope with unsupported toe using smartstone probes, Eng. Struct. 221, 111038, DOI: 10.1016/j.engstruct.2020.111038.

Ravindra, G.H.R., F.G. Sigtryggsdottir, and L. Lia (2020b), Buckling analogy for 2D deformation of placed ripraps exposed to overtopping, J. Hydraul. Res. 59, 1, 109-119, DOI: 10.1080/ 00221686.2020 .1744745 . 